\title{
Polymer Engineering - Developing or Improving Plastic Products- Are Plastics Boon or Bane?
}

\author{
Peter Eyerer ${ }^{1 *}$, Helmut Schüle ${ }^{2}$ and Peter Elsner ${ }^{1}$ \\ ${ }^{1}$ Fraunhofer Institute for Chemical Technology, Germany \\ ${ }^{2}$ University of Applied Sciences Kaiserslautern/Pirmasens, Germany
}

Submission: August 03, 2020; Published: August 19, 2020

*Corresponding author: Peter Eyerer, Fraunhofer Institute for Chemical Technology, Germany

\begin{abstract}
Plastics have advantages and disadvantages in properties like every other material section i.e. wood, metals, aluminum, ceramics. A boon is the high flexibility with plastics to create each desired property for each single application. But this is exactly also the bane. The result are the 5 Billon tons of plastic worldwide everywhere on earth. The diversity of plastic solutions is enormous. This makes reuse of it almost impossible. Compared with no economic value of used plastic the significance for Consumers and companies is almost zero. We need a common strength to solve this problem. And we need true facts from scientists and experts to help consumers make the wright decision under technical, economical, ecological and social aspects. This is shown in detail using a plastic tote bag versus a fiber tote bag.

Keywords: Polymer Engineering; Plastic Products; Advantages and Disadvantages; Boon and Bane of Plastics
\end{abstract}

\section{Introduction}

The "polymer" expertise in interaction with technological knowledge on raw materials, polymer materials, machine and process technology, processing, manufacturing technology and quality, tool and surface technology, construction and simulation, use, repair and recycling, cycles and disposal, Life Cycle Engineering (LCE) and Further training leads to qualified "polymer engineering" and is part of polymer science $[1,2]$. The specialists working in plastics technology also have enormous competitive advantages and behave sustainably through the application of the engineering concept to innovations in their products and in the quality of their work from a variety of particularly forwardlooking aspects (-> economy, component optimization, resource conservation, environmental compatibility, etc.). It should be noted at this point that specialist expertise within plastics technology is basically a reflection of our quality of life and thus our prosperity. This will certainly continue to be the case in future, provided that we are "qualified" and highly responsible when it comes to plastics!

\section{Present situation}

From today's perspective and also in the future, plastics from the following, exemplary selected areas of life will no longer be imaginable. a. Energy saving through lightweight construction (low density) with moving masses (cars, aircrafts, robots, satellites, rockets)

b. Electrical insulation (including electrical cables, electric motors)

c. Thermal insulation for buildings (foams)

d. Improved shelf life and hygiene of food (packaging)

e. Product protection / resource conservation through shock absorption (packaging)

f. Maximum mobility through rubber tires (traffic)

g. Seat belts in vehicles (shock absorption)

h. Electronic components (mass production)

i. Leisure experiences (skiing, climbing, hiking, ball games, bicycles, water sports, tennis, etc.)

j. Clothing, textiles (comfort, durability)

k. crop yields in agriculture (covers, nets, fences, irrigation, silage)

1. medical healing (bandages, syringes, tubes, plasters, implants etc.) 
And for all applications of plastics, these are usually inexpensive.

It should also be noted that due to their extremely high number of variants (materials made to measure for every application), plastics have, besides outstanding advantages (see above) as the boon side, also serious disadvantages (i.e.-> recycling problems) as the bane side.

For about 30 years we have been experiencing how plastics are gradually becoming discredited by public opinion due to "conspicuous" environmental events. These include (selection):

a. Fine dust pollution (microplastics) due to tire abrasion, sports fields with artificial turf,

b. Nanoparticles from cosmetics, fibers from clothing parts lead to plastic in the world's oceans, in the ground and in the air. Polymer particles (plastic primary particles) migrate through food intake in humans and animals

c. Recycling quotas and circular economy up to ban on disposable products in more and more countries worldwide

d. Consumer health as a result of emissions from packaging and insulation materials as well as floor coverings in the construction industry and much more. Think on PVC soft for example.

e. Reduced moisture absorption of arable soils due to mixed decomposition products made of PE from cover foils etc. over the years.

f. Emissions of additives in plastics (fogging) in new cars, home mobiles, textiles, household machines, departments (floors, furniture), buildings (Inside and outside: foams, surface protections), and so on.

Basically, it has to be demanded that the highest priority must be to generate an accurate factual awareness among consumers through honest, open education. Recognized undesirable developments and misalignments are to be named with clear and understandable names. It is just as important, however, to demonstrate and appreciate the indispensable, environmentally friendly, life-saving, and beautifying consequences of plastic applications.

Plastics are made-to-measure materials, and, from today's perspective, it is precisely this advantage that is increasingly becoming a major disadvantage with the current possibilities with regard to recycling and reuse (closed loop economy). However, this may change in the future. So "plastic waste", provided chemical recycling processes (catalytic cracking, etc.) further developed so that in the future the plastic itself will become a source of raw materials again, will receive a completely new appreciation Using solar energy, it is fundamentally possible to achieve a carbon-neutral, climate-friendly life cycle assessment! With glass, metal, ceramics, wood, the situation is similar with regard to a circular economy. Quantitatively smaller, unmixed material flows are significantly larger in number with plastics. With high-strength, alloy steel sheets for car bodies, there is the same problem of pure recycling in the second and subsequent life of a component that is subjected to comparable loads, such as in e.g. PVC window frames. For metals, the need for metals with lower properties is huge worldwide. Similar to thermoplastics, they can be melted and re-alloyed and finally used as normal steel, here, for example, structural steel. With 30-year-old PVC window frame formulations, this is also possible to a limited extent, but the volume flows that can be achieved are much lower at the same time significantly higher logistics costs. Additive developments over the decades also prevent their use after 20 years.

a. Without plastics, there would only be mobility based on wood, metal and ceramics (no rubber tires).

b. Without plastics, natural fibers for clothing would not be sufficient for all of humanity or the cultivated areas would be too scarce.

c. Without plastics, we used the oil for heating and transport even faster (plastics reduce resource consumption).

d. Without plastics, there would be no electrical devices, no electrical motors and electronic components

e. Without plastics we would have no surface protection (corrosion)

f. Without plastics, medical technology and hygiene would have been up to 100 years ago.

g. And without plastics there would be no space and aviation technology.

It is also correct, however, that the approximately 9 billion tons of plastics that have been extrapolated since 1950 (2 million t pa) up to 2020 including (approx. 420 million t pa) have a destructive impact on the world's oceans and that animals and plants suffer from it [3]. This last point is something to be deepened.

The chemical industry produces plastics from (only) $4 \%$ of the oil that is extracted annually. $45 \%$ each of oil flows into heating + cooling and traffic, another $4 \%$ into pharmaceutical products. These usual percentages of mass falsify the picture. Due to the low density of plastics $\left(0.1 \mathrm{~g} / \mathrm{cm}^{3}\right.$ for foams up to 2.0 for glass fiber reinforced composites) on average around 1.2 $\mathrm{g} / \mathrm{cm}^{3}$ ), their volumes are much larger. This is the only way to explain that landfills are overflowing, the landscape is polluted, and the oceans are full of discarded plastic products because 15 large rivers (4 of them in Europe) flush tons of waste into the oceans. Although it is people, some unscrupulously criminal, who dispose of plastics carelessly, the manufacturing industry and the legislature - here at the international level-would have been wise to take sustainable countermeasures decades ago. Immediate action and implementation of the measures are imperative here. According to a study by Geyer R, et al. [3], University of California (2017), 6.3 billion tons of plastic were generated by 2015. 600 million tons were processed into recycled materials at short 
notice and 800 million tons were incinerated. 4.9 billion tons are still in use or accumulate in landfills, in the countryside and in the seas. According to R. Geyer, around 34 billion tons of plastic will be produced until 2050. The plastic flood has to increase.

\section{Life Cycle Engineering}

If, on the one hand, the media make a very important contribution to uncovering all kinds of environmental crimes, the same breath is always used for a factual, serious presentation of the relationships waived. An unfounded uncertainty among consumers, often based on general statements, is created. Using the example of <comparison of carrier bags - made of polyethylene and fabric $\rightarrow$, the emotional wrong assessment of the population on the "culprit" plastic can be refuted. Holistic balancing and life cycle engineering are sophisticated methodological tools that are executed correctly and provide good support for decision making. They are misguided when carried out in a biased and incomplete or / and methodically improper manner. For example, the numbers in (Table 1) show that an ftb is more environmentally, technically, and economically disadvantageous than a ptb for some criteria (Figure 1).

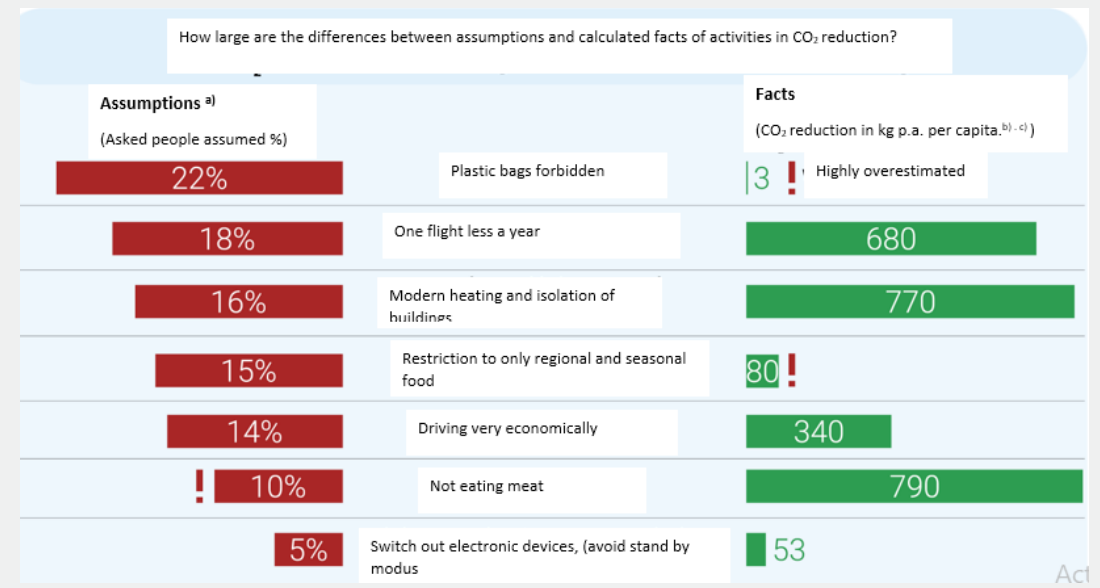

Figure 1: a) Representative online inquiry of 1500 German citizen above 18 years old, September 2019, b) calculation on basis of numbers of German Environment Foundation, $\mathrm{CO}_{2}$ online, Statistical Federal Office and c) $2716 \mathrm{~kg} \mathrm{CO}$ reduction per capita. are possible in Germany totally; in average one German citizen produces p.a. $10,000 \mathrm{~kg} \mathrm{CO}$.

Table 1: Comparison tote bags (tb): Plastic tote bag (ptb) versus fabric tote bag (ftb) (Different studies were used for the comparison. On their Compatibility has been respected, but is not always secured $[3,4]$.

\begin{tabular}{|c|c|c|}
\hline Criteria & Plastic- & Fabric tote bag \\
\hline Material & Tote bag (ptb) PE (polyethylene) & (ftb) Cotton \\
\hline $\begin{array}{c}\text { Mass } \\
\text { Mass content of tb in Germany }\end{array}$ & $0.3 \%$ in reusable plastic & $?$ \\
\hline Material per medium tb / Load capacity Content (Volume in ltr) & $20 \mathrm{~g} / 15-20 \mathrm{~kg}(18-22 \mathrm{ltr})$ & $\begin{array}{c}180 \mathrm{~g} \text { (factor } 9 \text { more }) / 25 \mathrm{~kg}(17 \\
-33 \mathrm{ltr})\end{array}$ \\
\hline $\begin{array}{c}\text { Primary energy } \\
\text { Energy consumption per medium tb }\end{array}$ & $0.45 \mathrm{kWh}$ & $8.01 \mathrm{kWh}$ (factor 19 more) \\
\hline $\begin{array}{l}\text { Resources } \\
\text { Oil consumption for tb per Citizens of Austria }\end{array}$ & $\begin{array}{l}0.66 \text { Liter Diesel approx. } 13 \mathrm{~km} \text { with small } \\
\text { car }\end{array}$ & $?$ \\
\hline Consumption of all tb in Germany & $0.08 \%$ of oil p.a. & $?$ \\
\hline $\begin{array}{c}\text { Emissions } \\
\text { GWP je tb in } \mathrm{kg} \mathrm{CO}_{2} \text { eq }\end{array}$ & $0.04 \mathrm{eq}$ & 0.9 eq (factor 22 more) \\
\hline $\begin{array}{l}\text { Use } \\
\text { Times of usage } \\
\text { Frequency of use from tb to break even at } \mathrm{CO}_{2} \text {-Consumption }\end{array}$ & $\begin{array}{l}1-3 \text { times (max. 8) } \\
1 \mathrm{x} / 2 \mathrm{x}\end{array}$ & $\begin{array}{l}\text { real numbers unknown } \\
\text { corresponding } 131 / 327 \text { Circuits } \\
\text { (theoretically) }\end{array}$ \\
\hline Number of tb used per EU citizen p.a. / per German & $\begin{array}{c}65 / 76 \text { (40 of them only one time used, } 36 \\
\text { multiple) }\end{array}$ & ? \\
\hline
\end{tabular}




\section{The following incident must also be mentioned}

In a bill by the German Federal Environment Ministry on November 6, 2019, Minister Svenja Schulze said in the Bundestag: "Plastic bags are the epitome of wasting resources. They are made from crude oil and are often only used for a few minutes." Anyone who violates the law can be fined up to $€ 100,000$. Here, as in the example below, the question really arises "Where is the proportionality based on facts and where is common sense?". The EU prohibits disposable drinking straws of a certain diameter range in 2019. Tecnaro company, Ilfeld, Germany has been supplying the straw market with $100 \%$ biopolymers that are quickly biodegradable since 2019. Unfortunately, the latter are no longer allowed because the EU administration apparently forgot to allow biopolymers.

\section{Conclusion}

Plastics have material advantages and disadvantages. A tailor-made material can usually be produced based on practical requirements. From today's perspective, the question of the disposal option is often disadvantageous. If plastic is to be used sensibly and sustainably in our world, it is the task of the specialists (chemists, physicists, engineers, business economists, educators, buyers and sellers) to deal with it professionally and competently from the perspective of society. It does not help the consumer and our earth to be told, that moldable thermoplastic plastics are recyclable economically but only if they are collected separately in plastic groups. The consumer, who has to deal responsibly with the available resources, also hold an outstanding position. However, this requires the truthful information required. As this unfortunately does not take place, as the state of our living environment shows worldwide, it is the task of the experts, together with national and international legislators, to provide prompt solutions to prevent the environmental problem from worsening and to introduce improvements.

\section{References}

1. Eyerer P (1979-2006) Kunststoffkunde, lecture at University Stuttgart, Germany.

2. Eyerer P, Schüle H, Elsner P (2020) Polymer Engineering, (2 ${ }^{\text {nd }}$ Edn), Springer Berlin, Germany, pp. 160.

3. Geyer R, Jambeck JR, Law KL (2017) production, use, and fate of all plastics ever made, Science Advances 3(7): e1700782.

4. Baitz M (2020) Personal Communication.

5. Held M (2020) Personal Communication.

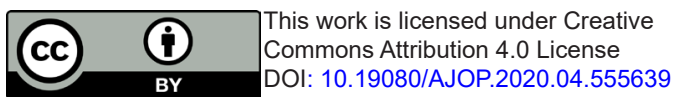

\section{Your next submission with Juniper Publishers will reach you the below assets}

- Quality Editorial service

- Swift Peer Review

- Reprints availability

- E-prints Service

- Manuscript Podcast for convenient understanding

- Global attainment for your research

- Manuscript accessibility in different formats ( Pdf, E-pub, Full Text, Audio)

- Unceasing customer service

Track the below URL for one-step submission https://juniperpublishers.com/online-submission.php 